Title: $\quad$ A Socio-Cognitive Approach to Service Quality and Adherence Amongst Elderly Patients: A Pilot Study

Authors: Lan Snell, The University of Sydney; Lesley White, The University of Sydney

\begin{abstract}
:
Purpose. To examine the relationship between patients' perceptions of emotional intelligence (EI), health competence, service quality and adherence behavior in the Home Medicines Review (HMR) setting.
\end{abstract}

Methodology. Qualitative data were obtained from in-depth interviews with 20 HMR patients. Participants were purposively recruited from different urban and regional areas in Australia.

Findings. We conceptualize service quality from a socio-cognitive perspective by incorporating psycho-socio factors such as EI and health competence as moderators to overall service quality and adherence. Our findings suggest that EI and health competence influence patient perceptions of service quality and non-adherence at multiple levels of abstraction.

Implications. Staff training and development programs that incorporate EI could improve service delivery which could increase patient perceptions of service quality and adherence. Designing intervention initiatives aimed at increasing patient awareness and education of their health conditions could also improve service quality perceptions and adherence behavior.

Originality. No study has yet examined service quality and non-adherence from a sociocognitive perspective.

Key Words. Research paper; service quality; adherence; emotional intelligence; health competence. 


\section{Introductory note:}

Author Bio: Lan Snell is a doctoral candidate at The University of Sydney. Her academic qualifications include a BBus from UTS, MEdLdhp (Education and Work) and a Post Graduate Certificate in Research Methods, both from Macquarie University. Contact details: +61 29420 3727; lansnell@ bigpond.net.au. Mailing correspondence: Lan Snell 9 Wingadee St, Lane Cove NSW 2066, Sydney Australia.

Professor Lesley White is the Johnson \& Johnson Pharmacy Practice Foundation Chair of Pharmacy Management at The University of Sydney. Lesley's interests focus on strategic marketing and services marketing, particularly services quality, together with small business and professional services marketing. Her qualifications include a BPharm, MCom, MEd and PhD. Contact details: +61 29351 4447; lesley.white@ sydney.edu.au. 


\section{Introduction}

Recent conceptualisations of health service quality suggest that service quality evaluations are derived from a number of sub-dimensions that influence their associated primary dimension, which in turn, influences overall quality perceptions. This hierarchical approach to service quality has been empirically supported in the marketing literature (e.g. Dabholkar et al. 2000, Brady \& Cronin 2001) and more recently confirmed within the context of health services (Dagger et al. 2007), where service quality is presented as a third-order factor model. While these findings significantly contribute to understanding the complex nature of consumer evaluations of health services, they do not examine (and nor was the intention) the relationship between specific socio cognitive states such as the consumer's emotional intelligence (EI) and health competence to adherence behavior.

Previous studies in health suggest that quality evaluations of provider behavior by patients with chronic diseases were significantly associated with self-report assessments of their own physical health, mental health and social circumstances (Greenley et al. 1982, Linn \& Sheldon 1982). These findings suggest that consumer perceptions of their health and emotional state could influence their assessment of the quality of provider services, and hence their overall perceptions of the service quality.

Non-adherence to medical regimes is a complex problem not only for individuals, but also for public health systems, and by extension, the wider economy. This is because adherence has been shown to be a key link between process and outcome in medical care (Vermeire et al. 2001) and numerous studies have sought to identify determinants of non-adherence (e.g. DiMatteo \& Hays 1980, Horne \& Weinman 2002, Mårdby et al. 2007). 
The objective of our study was to develop a socio cognitive approach to service quality and non-adherence within a specific service encounter: the Home Medicines Review (HMR). The HMR program is a government initiative aimed at improving patient health and well-being and involves the collaboration between the GP, pharmacist and patient in reviewing patient use of medicines.

\section{Service Quality}

Perceived quality is viewed as an attitude, resulting from comparisons or expectations with perceived performance. A number of evaluative criteria have been offered by the literature including the service environment, enabling factors and interpersonal quality (McDougall \& Levesque 1994, Rust \& Oliver 1994, Brady \& Cronin 2001). Acknowledging the similarities and semantic differences of these various approaches, Dagger et al (2007) suggest that service quality is comprised of four overarching dimensions: interpersonal quality, technical quality, environment quality, and administrative quality. However, not all these dimensions apply directly to health services, particularly to the HMR service encounter.

\section{Health Service Quality}

Donabedian (1966) suggests three main approaches to assessing health quality: outcomes (terms of recovery, restoration of function and survival); the process of care (patient perceptions of quality); and the setting (environmental factors). de Ruyer and Wetzels (1998) argue that outcomes are difficult to establish because of variability in patient health conditions and their physical and mental state. This variability has led to the concept of intermediate outcomes which are subjective measures such as the provider's ability to deliver the service (Murfin et al. 1995).

Donabedian's (1966) three approaches to assessing health service quality are featured in other conceptualisations of health service quality, and similar to the services marketing literature, 
the various health quality models contain overlapping dimensions (e.g. Choi et al. 2004, Zineldin 2006). Although we accept that both outcome and process play an integral part in the service encounter, the focus of the present research is on the process of care given the unique context of the HMR. We were not concerned with making any clinical assessments hence exploring definitive outcomes was outside the scope of the research aims. Rather, we were interested in understanding subjective measures (intermediate outcomes), such as patient psycho-socio attributes and their relationship to perceived service quality and adherence behavior.

\section{Adherence}

Adherence refers to the degree to which a patient's behavior (in terms of taking medication, following diets, or executing lifestyle changes) coincides with medical or health advice (Haynes et al. 1976), whereas compliance implies obedience to the health care professional (Chisholm-Burns \& Spivey 2008). Although both terms have been used interchangeably in the literature, some researchers have argued that the term adherence is preferable to compliance in that it reduces the attribution of greater power to the doctor in the provider-patient relationship which compliance brings (Morisky et al. 1986, Lutfey \& Wishner 1999, Vermeire et al. 2001).

Adherence research is plagued with debate, much of which relates to the complex nature of non-adherence (Stephenson et al. 1993) and issues surrounding its measurement (Roth 1987). In response, some researchers have identified sub-types of non-adherence such as intentionality (Donovan \& Blake 1992), whereas other more recent attempts have narrowed adherence down to the patient's behavior in taking their prescribed medication. The term pharmacoadherence refers to "the extent to which a patient follows a given therapeutic medication regime as agreed on in partnership with a health care professional" (Chisholm-Burns \& Spivey, 2008, p.661). Given the 
HMR context, pharmacoadherence, that is, the patients' perceived ability to adhere to their medication management plan post their HMR, was used as the unit of analysis.

\section{Perceived Health Competence}

Smith et al (1995) developed the Perceived Health Competence Scale (PHCS) aimed to assess efficacy/competency beliefs of one's health. Specifically, the PHCS is a measure of a person's expectancy that he/she can effectively interact with his/her environment (Wallston 1992). Wallston (1992) argues that this type of generalized expectancy combines a behavioral expectancy (e.g. "I am capable of doing the behavior") with an outcome expectancy (e.g. "The behavior will get me what I want") (p.194). On the basis of findings from other studies that have used the PHCS and demonstrate the construct validity of the scale (for a review, see Smith et al. 1995), the PHCS was used in this study given the health domain of the study.

\section{Emotional Intelligence (EI)}

Broadly, EI refers to the interaction between emotion and cognition that leads to adaptive functioning (Salovey \& Grewal 2005). EI has been conceptualised as consisting of three adaptive abilities: appraisal and expression of emotion; regulation of emotion; and utilisation of emotions in solving problems (Salovey et al. 2000). Each of these abilities feature sub-components related to the adaptive use of cognition from an intrapersonal (ability to know one's own emotions) and interpersonal (ability to understand other individual's emotions and intentions) perspectives (Gardner 1983). Previous studies have found that those with enhanced interpersonal skills with high EI would have better psychosocial functioning (Schutte et al. 1998, Brown \& Schutte 2006), including intrapersonal factors such as mood regulation and optimism (Austin et al. 2005), and more satisfaction with social support (Vale et al. 2002). 
We argue that because the HMR encounter is a social interaction between the health care provider and the patient, understanding the patients' EI might help explain possible differences in interpersonal quality evaluations. For example, the extent to which the patient adopts certain perspectives of other people might help account for variances in service quality perceptions which might influence the patients' adherence behavior.

\section{Sample}

Participants were purposively recruited from different urban and regional areas in Australia. Qualitative data were obtained from in-depth interviews with $20 \mathrm{HMR}$ patients. Eight of these were male and 12 female. Respondents ranged from 44 to 90 years of age. The criteria for patient participation included English speaking participants who previously had a HMR (within three months of the interview date). Each interview was conducted at a mutually convenient location, with the majority (19) being conducted within the patient's home. The average interview time was 50 minutes.

\section{Methodology}

The interview questions were based on a review of the literature from disciplines including services marketing, socio sciences, medicine, pharmacy practice and psychology. Interviews were audio recorded and transcribed verbatim. Pseudonyms have been used to mask the identity of patients (e.g. P1, P2, P3 etc) and their accredited pharmacist (pseudo names).

For overall service quality perceptions, respondents were asked to describe the factors they believed were necessary for a quality HMR. Items from the Health Service Quality Scale (Dagger et al. 2007) were used to facilitate the discussion. Respondents were encouraged to identify specific attributes they perceived as influences on these primary dimensions, with one exception. Support environment quality was eliminated in this study because the majority of 
HMR's were conducted in the home environment and therefore the associated environmental features that could influence perceptions such as atmosphere and tangibles, do not apply in this situation.

Patient adherence was discussed using adapted items from the General Adherence Scale (Sherbourne et al. 1992), the Self-Reported Medication-Taking Scale (Morisky et al. 1986), and the Medication Adherence Report Scale (MARS; Horne \& Weinman 2002). Questions such as "Have you been able to stick to the plan?", "What factors have helped you adhere to the plan?" and "What were some of the difficulties you experienced in adhering to your plan?" were asked.

Items from the Perceived Health Competence Scale (PHCS; Smith et al. 1995) were used to frame discussions on patient health competence or self-efficacy. Items from two scales were adapted to facilitate the EI discussion. These include the Assessing Emotions Scale (AES; Schutte et al. 1998) for assessing EI as a trait and the Interpersonal Reactivity Index (IRI; Davis 1980). Initially, questions regarding the respondents' perceived interpersonal skills were asked. For example: "Would other people find it easy to confide in you?" and "Do you regard yourself as someone who can 'read' other people's body language?" A hypothetical scenario was also used to gain additional information regarding patients' EI levels, with particular attention to EI components such as interpersonal skills, social relations and empathy.

\section{Validity}

Construct validity was increased by adhering to the "three principles of data collection" (Yin 2003, p.97). The first principle was met by use of direct observations. The second principle was represented by the establishment of a case study database in the form of a case study protocol. The case study protocol, including interview schedules, was developed to record and monitor all the procedures for the data collection (Perry 1998). The interview schedule was 
piloted with two participants who did not participate in the main study. Minor changes were made to the wording of the questions, and refinements made to the probes. In all instances, maintaining a chain of evidence, the third principle, was used as the overarching analysis guideline. This was achieved by extensive note taking, as reflected in our constant updates of the protocol.

\section{Analysis}

The sequence of analysis followed a complete transcription of each interview, which was verified and supplemented by our field notes and other supporting documentary evidence (e.g. feedback from the pharmacist). Initially, we categorized all the data in an attempt to intuitively aggregate units (Stake 1995). We then analysed the data by noting patterns and memoing (Miles \& Huberman 1994), searching for similarities, recurring themes and emergent issues and relationships in the data (Miles \& Huberman 1994). We repeated this process several times until a general set of themes emerged from the data.

\section{Research Findings}

\section{Patient Characteristics}

The majority of respondents (15) were elderly (65 or above) with 12 of the overall sample female. All respondents achieved primary school education, with three achieving partial secondary level education. Nineteen respondents were on some kind of government welfare (e.g. aged pension, widow pension, disability pension, ex-serviceman pension, carer's pension).

With regard to employment history, the majority of female respondents (9) had worked in a part-time or casual capacity in retail, two were unemployed and one female respondent had recently retired from a career in finance. The occupation of the male respondents had ranged 
from sales, agriculture, military services and building. All respondents had retired because of age or ill health.

\section{Health Conditions}

The medical histories of most respondents were lengthy and complex. Respondents suffered from a variety of health conditions, ranging from acute illness to chronic illness. Selfreported health conditions included cardiovascular, respiratory, diabetes, cancer, gastro-intestinal, arthritis, cataracts, mental illness, neurological and osteoporosis. Table 1: Health Conditions, summarises these conditions.

\section{INSERT TABLE 1 ABOUT HERE}

To assess the patient's understanding of their medication and health condition(s), questions regarding their current medications were asked. Half the respondents said they were taking 5-7 different types of medication, with five taking eight or more medications. Furthermore, 11 of the respondents were taking more than 10 doses of medication per day. Of the types of medication, many of the respondents (12) were on medication with a narrow therapeutic index and/ or requiring therapeutic monitoring (e.g. warfarin).

\section{HMR Encounter}

When asked to recall (unprompted) what the pharmacist discussed with them, most respondents said the pharmacist covered the range of their medications (17), followed by the function of effect of various medications (11) and when and how medications should be taken (8). Table 2: Topics Discussed by Pharmacist, summarises the range of topics recalled by the participant as being covered by the pharmacist.

INSERT TABLE 2 ABOUT HERE 


\section{Service Quality}

The findings suggest that each one of the three primary dimensions of service quality (interpersonal, technical and administrative) has at least two sub-dimensions. The following section discusses these sub-dimensions according to their parent dimension.

\section{Interpersonal Quality}

The data identified a number of recurring themes including: trust, communication, rapport and respect. Respondents made common references to the importance of trust or confidence in the pharmacist. The following statements exemplify the perceived importance of this attribute:

"as you're dealing with medications, you got to trust them and have confidence in them" (P6); and

"they know more than I do, so if they say something, it must be right, it's got to be right. . . I place a lot of trust in doctors" (P11).

Communication was identified as another important aspect of interpersonal quality. For example, respondents made the following statements:

"the ability to translate [medications] to you in plain English" (P1); and

"you've got to have someone there that can talk and that you can talk back, like conversation" (P12).

Rapport, another theme related to communication, was identified in the data. Respondents indicated that they could relate well with the pharmacist because of the pharmacists' rapport building skills which made them feel comfortable, enabling them to trust 
the pharmacist and communicate effectively with them. This is reflected in statements such as: "It's easy to have a rapport with him" (P13);

“She made you feel comfortable. ... Y You didn't feel uneasy when you're talking to her, she was easy to ask questions" (P2); and

"She chatted about her kids, she just made you feel comfortable so that you felt you were just sitting down having a chat and within that chat she was giving you her knowledge so that you knew" (P9).

Respondents made the following statements regarding the importance of respect and empathy:

"they need to speak to me as not beneath them, looked down upon" (P3);

“he doesn't make you feel like a nutter, he treats you like a normal human being" (P7); and

“not speaking like a doctor" (P15).

\section{Technical Quality}

The data suggests that respondents evaluate competence of their pharmacist based on perceived knowledge, credentials and perceived experience. The following statements support this view:

"knowledge is absolutely important as you're dealing with medications" (P4);

“they've got to have knowledge too, you've got to have someone that's been in that sort of thing for a long while" (P3); and 
"my pharmacist is excellent because she lectures in medicine at the university and I thought, that's who I want, that's someone who's obviously up to date" (P9).

Furthermore, the data suggests that the majority of respondents (17) base their evaluations of the medical care process on interpersonal qualities of the provider:

"I don't know if they know what they know, but she was nice and I liked her" (P11); and “they have to know what they're talking about I suppose, but I wouldn't know" (P14).

\section{Administrative Quality}

Two core themes were identified within administrative quality: timeliness and collaborative support. Respondents frequently expressed how surprised and happy they were regarding the timeliness of the HMR process. These include the time from which the initial recommendation of a HMR from either their pharmacist or GP was made, to the time of the actual HMR encounter which was in most cases less than two weeks.

Collaborative support was the second sub-dimension identified by the data. Respondents identified this as follow-up actions exhibited by heath care service providers post review, citing examples of communication or actions between the pharmacist and GP, and the GP to patient to verify this. For example:

"she was great because she did what she said she would do. . . I found out from my GP" (P5); and

"I guess they spoke to each other because that's why my medication changed" (P12).

A relationship between collaborative support and the role of the patient in how they manage their medication plan was also observed from the data. Five patients identified themselves as active in their medication management. For example: 
"I have a very, very thorough understanding of my medications which [my pharmacist] has acknowledged that I truly do understand what I do with them, not just what each medication does, but the interactions that the medications can have. . . Because I take a lot of medication, I need to understand the interplay and particularly if I'm taking anything that is an over-the-counter medication" (P7).

The majority of respondents (15) however, assumed a more passive role. For example: "I wouldn't know" (P3); “they're the experts" (P8); and "I just do what I'm told" (P14). The findings indicate that the collaborative quality element is viewed primarily as the interaction between health service providers, and not the patient.

\section{Adherence}

The majority of respondents held the belief that they take too many medications, with most expressing a degree of concern regarding addiction:

"I'm terrified of pethidine because I can understand why people get addicted because of that calm, relaxed feeling" (P6).

Other respondents (6) expressed a desire to eliminate some of their medications because of adverse drug reactions. Fear of addiction and or adverse drug effects led some respondents to modify their regime by taking themselves off certain medications, not taking medications and or switching medications. In some cases, these non compliant practices were done without consultation with their GP. For example, one respondent with a medical history including bowel cancer, depression, epilepsy and a previous addiction to narcotics, and whose medication plan includes eight different drugs stated: 
"Tegretol is the only medication I have to take, all the rest I need to get off. . . . I have gotton myself off some of these and feel better" (P9).

Many respondents had difficulty in identifying and or integrating symptomatic experiences with information provided by health professionals, which contributed to misconceptions regarding their health condition(s). The data is rich with examples of these adaptation behaviors:

"I felt that I could do without them 'cause I don't like taking tablets, then I thought the doctor was giving me the wrong medication you know, I didn't take them and it made me sick and I ended up in hospital. . . . When I came out I started taking them properly" (P10); and

"I was in hospital and had pneumonia and I was taking all this cortisone and was getting fatter and fatter, I don't believe that weight helps your pain, but you start to put on weight you know, and I stopped taking them because of the weight" (P15).

Despite these non-adherent practices, when asked specifically if respondents have been able to stick to their medical regime, all respondents stated that they did.

When asked about beliefs relating to the respondents' prescriptions, the majority of participants acknowledged that their health condition was dependent on their medications. For instance:

"I have to take pain killers to cope with arthritis, osteoarthritis and fibromyalgia" (P6); and

"you've got to take your medications, you know, the older you get, the pain gets worse, so I've got to take them as I want some quality of life" (P16). 
Attributing adherence from a cost-benefit perspective was also observed. Some respondents indicated that because of financial issues, they could not afford some of their medications, and weighed the decision to stop particular medications on the perceived benefits of the treatment. The following statement verifies this belief:

"Because I'm on the Carer's pension, I haven't had the finances to get the prescriptions even though it might only be $\$ 10$ so I go without for a week" (P6).

\section{Perceived Health Competence (PHC)}

In terms of perceived health competence, only two respondents said that they did not have a good understanding of their health conditions. Respondents were asked to describe ways in which they undertook other initiatives to gain additional knowledge about their health conditions. Four respondents said they conducted additional research by either talking to other health professionals or by subscribing to medical newsletters relevant to their health condition. The remaining 16 respondents indicated that they did not seek any additional information regarding their health conditions.

\section{Emotional Intelligence (EI)}

The data provided rich information as to perceived intra and inter personal skills. Ten of the female respondents believed that it was easy for people to confide in them, compared to five of the male respondents. The majority of female respondents (8) felt they were guided more by their heart than their head, whereas the majority of male respondents (6) indicated they were guided more by their head than heart. In terms of whether respondents felt they could read other people's body language, the data was evenly split between those who thought they could and 
those who thought they could not. This equal split was evident also between female and male respondents.

EI levels were additionally assessed by asking respondents how they would respond to the following hypothetical HMR encounter:

"Imagine that the pharmacist who conducted your HMR was short with you. You thought they rushed the review without giving you the appropriate time. What would you think/ do?"

Of the female respondents, four displayed an empathetic attitude toward the pharmacist with statements such as:

"I think I'd be understanding, I'd feel he had a busy life and that had would more than likely account for his behavior" (P3); and

"No I'd feel that something was happening to her, like the other day when she came and she was upset cause her friend died, I mean I would have been hurt, you know if people are short with you, but no one knows what going on with other people's lives, but I'd still feel hurt if they were rude" (P12).

Seven female respondents displayed less empathic concern, with most indicating that they might feel hurt or annoyed and attributed blame to the pharmacist:

“she was probably feeling miserable and cranky and didn't want to come anyway, so she's taking it out on me" (P2).

The majority of male respondents (7) also displayed little empathic concern, albeit with less feeling or attribution of self-blame. Statements such as: 
“I wouldn't take notice of it at all. It would not worry me, why should it worry me if they don't do their job properly, it's not my fault. ... Nothing affects me" (P7); and

"I'd tell him he's wasting his time and he's wasting my time too" (P16) exemplify this lack of concern.

The data suggests that overall, female respondents are more emotionally intelligent than male respondents. A higher number of females indicated they had good relations with other people, signified by the accompanying stories of relationships with family members or friends recalled when discussing whether they thought it was easy for people to confide in them. Comparatively, a lower number of males indicated that they had difficulty in interacting with people which lead them to believe that people did not easily confide in them.

\section{Discussion}

Consistent with findings from previous research (Carman 1990, Brady \& Cronin 2001, Dagger et al. 2007), the data suggests that service quality evaluations are highly complex processes, with most respondents identifying service quality at multiple levels of abstraction. The complexity of perceived service quality is evident from the number of confounding factors observed from the data. These relate mainly to the credence properties of health services which make it hard for patients to distinguish between interpersonal and technical dimensions of quality. Data from the present study support this view in that respondents identified technical quality based on the interpersonal attitudes and behaviors of their provider during the HMR encounter.

Non-adherence behavior, similar to perceived service quality, was found to be a highly complex phenomenon. The data provides rich examples of how patients model their representations of perceived threats and the procedures they use to manage their medications, revealing the multidimensionality of complex social and contextual factors of individual 
cognition and affect. Despite the non-adherent practices identified, when asked specifically if respondents have been able to stick to their medical regime, all respondents stated that they did. This unanimous response was unsurprising given findings from past studies that suggest patients tend to underestimate missed dosages and or overestimate the extent to which they comply (Bergman \& Werner 1963, Park \& Lipman 1964, Roth \& Caron 1978), and the tendency to respond in a socially desirable manner.

The hypothetical scenario used to facilitate the EI discussion was purposely designed to explore patient responses to a negative interaction, given other studies that found that most HMR patients viewed the encounter as positive (e.g. Schwartzkoff 2005). Negative social interactions might be a distinct dimension of social support and past studies have found a link between negative social interaction and psychological well-being (Rook 1984, Abbey et al. 1985). The findings from this study suggest that females were more emotionally intelligent than males. This is consistent with other studies which suggest EI might vary with gender (Schutte et al. 1998, Van Rooy et al. 2005, Goldenberg et al. 2006).

\section{Limitations}

We recognise the limitations associated with interpretations from the small sample size $(n=20)$. The purposeful nature of the sample means that caution is necessary in drawing general conclusions from the information provided in this study. Finally, the study recognises the limitations associated with the criteria of English-speaking patients as exclusionary of other cultural perspectives and or minority groups.

\section{Conclusion and Guidelines for Future Research}

Overall, the findings suggest that patient perceptions of their health and emotional state are important factors of the quality assessment of provider services, which influence their overall 
perceptions of service quality and adherence. We contribute to understanding service quality and adherence by conceptualising service quality from a socio-cognitive perspective incorporating factors such as EI and health competence as moderators to overall service quality and nonadherence. No study has yet examined service quality and non-adherence from this integrated perspective. Second, the findings suggest that EI and health competence influence patient perceptions of service quality and non-adherence at multiple levels of abstraction and health care providers who acknowledge the influencing role of EI and health competence can develop a more targeted approach during their service delivery interactions. These actions have the potential to enhance quality perceptions and importantly, patient adherence.

Additional work is needed is empirically test these relationships. Other areas for future research are to investigate these relationships from a dyadic or triadic perspective, involving providers and or powerful others. Furthermore, these relationships can be explored in other health contexts, for example, dentistry, weight loss or smoking cessation programs. 


\section{References}

Abbey, A., Abramis, D. J. \& Caplan, R. D. (1985). Effects of different sources of social support and social conflict on emotional well-being. Basic and Applied Social Psychology, 6(2), pp. 111-129.

Austin, E. J., Saklofske, D. H. \& Egan, V. (2005). Personality, well-being and health correlates of trait emotional intelligence. Personality and Individual Differences, 38(3), pp. 547-558.

Bergman, A. B. \& Werner, R. J. (1963). Failure of children to receive penicillin by mouth. The New England Journal of Medicine, 268(Jun 13), pp. 1334-1338.

Brady, M. K. \& Cronin, J. (2001). Some new thoughts on conceptualizing perceived service quality: A hierarchical approach. Journal of Marketing, 65(3), pp. 34-49.

Brown, R. F. \& Schutte, N. S. (2006). Direct and indirect relationships between emotional intelligence and subjective fatigue in university students. Journal of Psychosomatic Research, 60(6), pp. 585-593.

Carman, J. M. (1990). Consumer perceptions of service quality: An assessment of the SERVQUAL dimensions. Journal of Retailing, 66(1), pp. 33-56.

Chisholm-Burns, M. A. \& Spivey, C. A. (2008). Pharmacoadherence: A new term for a significant problem. American Journal of Health-System Pharmacy, 65(7), pp. 661-667.

Choi, K. S., Cho, W. H., Lee, S., Lee, H. \& Kim, C. (2004). The relationships among quality, value, satisfaction and behavioral intention in health care provider choice: A South Korean study. Journal of Business Research, 57(8), pp. 913-921.

Dabholkar, P. A., Shepherd, C. D. \& Thorpe, D. I. (2000). A comprehensive framework for service quality: An investigation of critical conceptual and measurement issues through a longitudinal study. Journal of Retailing, 76(2), pp. 139-174.

Dagger, T. S., Sweeney, J. C. \& Johnson, L. W. (2007). A hierarchical model of health service quality: Scale development and investigation of an integrated model. Journal of Service Research, 10(2), pp. 123142. 
Davis, M. H. (1980). A multidimensional approach to individual differences in empathy". JSAS Catalog of Selected Documents in Psychology, 10(85), pp. 2-19.

de Ruyter, K. \& Wetzels, M. (1998). On the complex nature of patient evaluations of general practice service. Journal of Economic Psychology, 19(5), pp. 565-590.

DiMatteo, R. M. \& Hays, R. (1980). The significance of patients' perceptions of physician conduct: A study of patient satisfaction in a family practice centre. Journal of Community Health, 6(1), pp. 18-34.

Donabedian, A. (1966). Evaluating the quality of medical care. Milbank Memorial Fund Quarterly, 44(44), pp. 3.

Donovan, J. L. \& Blake, D. R. (1992). Patient non-compliance: Deviance or reasoned decision-making? Social Science \& Medicine, 34(5), pp. 507-513.

Gardner, H. (1983) Frames of Mind: The Theory of Multiple Intelligences, New York, Basic Books.

Goldenberg, I., Matheson, K. \& Mantler, J. (2006). The assessment of emotional intelligence: A comparison of performance-based and self-report methodologies. Journal of Personality Assessment, 86 (1), pp. 33-45.

Greenley, J. R., Young, T. B. \& Schoenherr, R. A. (1982). Psychological distress and patient satisfaction. Medical Care, 20(4), pp. 373-385.

Haynes, B. R., Taylor, D. W. \& Sackett, D. L. (1976) Compliance in Health Care, Baltimore, John Hopkins University Press.

Horne, R. \& Weinman, J. (2002). Self-regulation and self-management in asthma: Exploring the role of illness perceptions and treatment beliefs in explaining non-adherence to preventer medication. Psychology \& Health, 17(1), pp. 17-32.

Linn, L. S. \& Sheldon, G. (1982). Patient suffering and patient satisfaction among the chronically ill. Medical Care, 20(4), pp. 425-431.

Lutfey, K. E. \& Wishner, W. J. (1999). Beyond "compliance" is "adherence". Diabetes Care, 22(4), pp. 635-639. 
Mårdby, A.-C., Åkerlind, I. \& Jörgensen, T. (2007). Beliefs about medicines and self-reported adherence among pharmacy clients. Patient Education and Counseling, 69(1-3), pp. 158-164.

McDougall, G. H. \& Levesque, T. J. (1994). A revised view of service quality dimensions: An empirical investigation. Journal of Professional Service Marketing, 11(1), pp. 189-209.

Miles, M. B. \& Huberman, M. A. (1994) Qualitative Data Analysis: An Expanded Sourcebook, London, Sage Publications.

Morisky, D. E., Green, L. W. \& Levine, D. M. (1986). Concurrent and predictive validity of a selfreported measure of medication adherence. Medical Care, 24(1), pp. 67-74.

Murfin, D. E., Schlegelmilch, B. B. \& Diamantopoulos, A. (1995). Perceived service quality and medical outcome: An interdisciplinary review and suggestions for future research. Journal of Marketing Management, 11(1-3), pp. 97-117.

Park, L. C. \& Lipman, R. S. (1964). A comparison of patient dosage deviation reports with pill counts. Psychopharmacologia, 6(4), pp. 299-302.

Perry, C. (1998). Processes of a case study methodology for postgraduate research in marketing. European Journal of Marketing, 32(9/10), pp. 785-802.

Rook, K. S. (1984). The negative side of social interaction: Impact on psychological well-being. Journal of Personality and Social Psychology, 46(5), pp. 1097-1108.

Roth, H. P. (1987). Measurement of compliance. Patient Education and Counseling, 10(2), pp. 107-116.

Roth, H. P. \& Caron, H. S. (1978). Accuracy of doctors' estimates and patients' statements on adherence to a drug regimen. Clinical Pharmacology and Therapeutics, 23(3), pp. 361-370.

Rust, R. T. \& Oliver, R. L. (1994). "Service quality: Insights and managerial implications from the frontier", in Rust, R. T. \& Oliver, R. L. (Eds.) Service Quality: New directions in Theory and Practice. CA, Sage Publications, Thousand Oaks.

Salovey, P. \& Grewal, D. (2005). The science of emotional intelligence. Current Directions in Psychological Science, 14(6), pp. 281-285. 
Salovey, P., Rothman, A. J., Detweiler, J. B. \& Steward, W. T. (2000). Emotional states and physical health. American Psychologist, 55(1), pp. 110-121.

Schutte, N. S., Malouff, J. M., Hall, L. E., Haggerty, D. J., Cooper, J. T., Golden, C. J. \& Dornheim, L. (1998). Development and validation of a measure of emotional intelligence. Personality and Individual Differences, 25(2), pp. 167-177.

Schwartzkoff, J. (2005) Investigator Initiated Guild Government Grant 2004-526. Evaluation of HMR Program.

Sherbourne, C. D., Hays, R. D., Ordway, L., DiMatteo, R. M. \& Kravitz, R. L. (1992). Antecedents of adherence to medical recommendations: Results from the medical outcomes study. Journal of Behavioral Medicine, 15(5), pp. 447-468.

Smith, M. S., Wallston, K. A. \& Smith, C. A. (1995). The development and validation of the Perceived Health Competence Scale. Health Education Research, 10(1), pp. 51-64.

Stake, R. E. (1995) The Art of Case Study Research, Sage Publications Inc.

Stephenson, B. J., Rowe, B. H., Haynes, R. B., Macharia, W. M. \& Leon, G. (1993). The rational clinical examination. Is this patient taking the treatment as prescribed? Journal of American Medical Association, 269(21), pp. 2779-2781.

Vale, M. J., Jelinek, M. V., Best, J. D. \& Santamaria, J. D. (2002). Coaching patients with coronary heart disease to achieve the target cholesterol: A method to bridge the gap between evidence-based medicine and the "real world"- randomized controlled trial. Journal of Clinical Epidemiology, 55(3), pp. 245-252. Van Rooy, D. L., Alonso, A. \& Viswesvaran, C. (2005). Group differences in emotional intelligence scores: Theoretical and practical implications. Personality and Individual Differences, 38(3), pp. 689-700. Vermeire, E., Hearnshaw, H., Van Royen, P. \& Denekens, J. (2001). Patient adherence to treatment: three decades of research. A comprehensive review. Journal of Clinical Pharmacy \& Therapeutics, 26(5), pp. $331-342$.

Wallston, K. A. (1992). Hocus-pocus, the focus isn't strictly on locus: Rotter's social learning theory modified for health. Cognitive Therapy and Research, 16(2), pp. 183-199. 
Yin, R. K. (2003) Case Study Research - Design and methods, Newbury Park, CA, Sage.

Zineldin, M. (2006). The quality of health care and patient satisfaction: An exploratory investigation of the 5Qs model at some Egyptian and Jordanian medical clinics. International Journal of Health Care Quality Assurance, 19(1), pp. 60-92. 
Table 1

Health Conditions

\begin{tabular}{|c|c|c|}
\hline Health Condition & & Frequency \\
\hline \multirow[t]{6}{*}{ Cardiovascular } & Hypertension (high blood pressure) & 11 \\
\hline & Angina (chest pain) & 4 \\
\hline & Infarct (heart attack) & 2 \\
\hline & Hyperlipidemia (high cholesterol) & 7 \\
\hline & Arrhythmia (irregular heart beat) & 1 \\
\hline & Peripheral vascular (blocked arteries) & 1 \\
\hline \multirow[t]{2}{*}{ Respiratory } & $\begin{array}{l}\text { Emphysema (Chronic obstructive airway } \\
\text { diseases) }\end{array}$ & 4 \\
\hline & Asthma & 7 \\
\hline Diabetes & & 7 \\
\hline Cancer & & 3 \\
\hline \multirow[t]{2}{*}{ Gastro-intestinal } & Reflux, ulcer & 4 \\
\hline & Irritable bowl & 3 \\
\hline Arthritis & & 7 \\
\hline Cataracts & & 1 \\
\hline Mental illness & & 5 \\
\hline Neurological & Stroke/ mini strokes & 2 \\
\hline Osteoporosis & & 6 \\
\hline
\end{tabular}




\section{Table 2}

\section{Topics Discussed by Pharmacist}

\begin{tabular}{|lc|}
\hline Topics Discussed & $\begin{array}{c}\text { Frequency of } \\
\text { Recall }\end{array}$ \\
\hline The range of medications used & 17 \\
When and how medicines are taken & 8 \\
Remembering what to take when & 2 \\
Function of effect of various medications & 11 \\
What can happen of medications are not used & 7 \\
correctly & \\
Side effects of medications & 4 \\
Storage of medications & 1 \\
Use of equipment e.g. puffers, spacers, dosette box & 7 \\
etc. & 1 \\
Other & \\
\hline
\end{tabular}

